\title{
FOLICULITE EOSINOFÍLICA TRATADA COM IMUNOGLOBULINA HUMANA POLIESPECÍFICA EM CONTEXTO DE NEOPLASIA HEMATOLÓGICA
}

\author{
Diogo Matos', Hugo Barreiros², Ricardo Coelho 3 , Henriqueta Cunha3, Elvira Bártolo4, Fernanda Vargas 5 \\ IInterno do Internato Complementar de Dermatologia e Venereologia/Resident, Dermatology and Venereology, Hospital Garcia de \\ Orta, Almada, Portugal \\ ${ }^{2}$ Dermatologista /Dermatologist, Centro Dermatologia Epidermis, Instituto CUF, Porto, Portugal \\ ${ }^{3}$ Assistente Hospitalar de Dermatologia e Venereologia/Consultant, Dermatology and Venereology, Hospital Garcia de Orta, \\ Almada, Portugal \\ ${ }^{3}$ Assistente Hospitalar de Dermatologia e Venereologia/Consultant, Dermatology and Venereology, Hospital Garcia de Orta, \\ Almada, Portugal \\ ${ }^{4}$ Chefe de Serviço de Dermatologia e Venereologia, Directora do Serviço de Dermatologia e Venereologia/Chief and Head of \\ Dermatology and Venereology Department, Hospital Garcia de Orta, Almada, Portugal \\ ${ }^{5}$ Assistente Hospitalar de Hematologia/Consultant, Haematology, Hospital Garcia de Orta, Almada, Portugal
}

PALAVRAS-CHAVE - Eosinofilia; Foliculite; Imunoglobulinas intravenosas; Leucemia linfocítica crónica de células B.

\section{B-CELL CHRONIC LYMPHOCYTIC LEUKEMIA-ASSOCIATED EOSINOPHILIC FOLLICULITIS SUCCESSFULLY TREATED WITH INTRAVENOUS IMMUNOGLOBULIN}

KEY-WORDS - Eosinophilia; Folliculitis; Immunoglobulins, intravenous; Leukemia, Lymphocytic, chronic, B-cell.

Conflitos de interesse: Os autores declaram não possuir conflitos de interesse. No conflicts of interest.

Suporte financeiro: $\bigcirc$ presente trabalho não foi suportado por nenhum subsídio ou bolsa. No sponsorship or scholarship granted. Direito à privacidade e consentimento escrito / Privacy policy and informed consent: Os autores declaram que pediram consentimento ao doente para usar as imagens no artigo. The authors declare that the patient gave written informed consent for the use of its photos in this article.

Recebido/Received - Maio/May 2015; Aceite/Accepted - Junho/June 2015

Correspondência:

Dr. Diogo Matos

Serviço de Dermatovenereologia - Hospital Garcia de Orta

Avenida Torrado da Silva

2801-951 Almada, Portugal

Email: diogomatos.pt@gmail.com

\section{CASO CLÍNICO}

Homem de 74 anos de idade, com o diagnóstico de leucemia linfocítica crónica de células B (LLC) estadio IV (linfocitose absoluta, anemia e adenopatias mesentéricas $>6 \mathrm{~cm}$ ) com 5 anos de evolução, já tratado com fludarabina, COP (ciclofosfamida, vincristina e prednisolona) e alemtuzumab com resposta hematológica parcial. É referenciado à nossa consulta por uma dermatose ligeiramente pruriginosa, com 2-3 meses de evolução, afectando predominantemente a face, região superior do tronco e membros superiores. Ao exame objectivo eram evidentes nódulos eritemato-purpúricos com necrose central, bem como pápulas, pústulas e 


\section{Carta ao Editor}
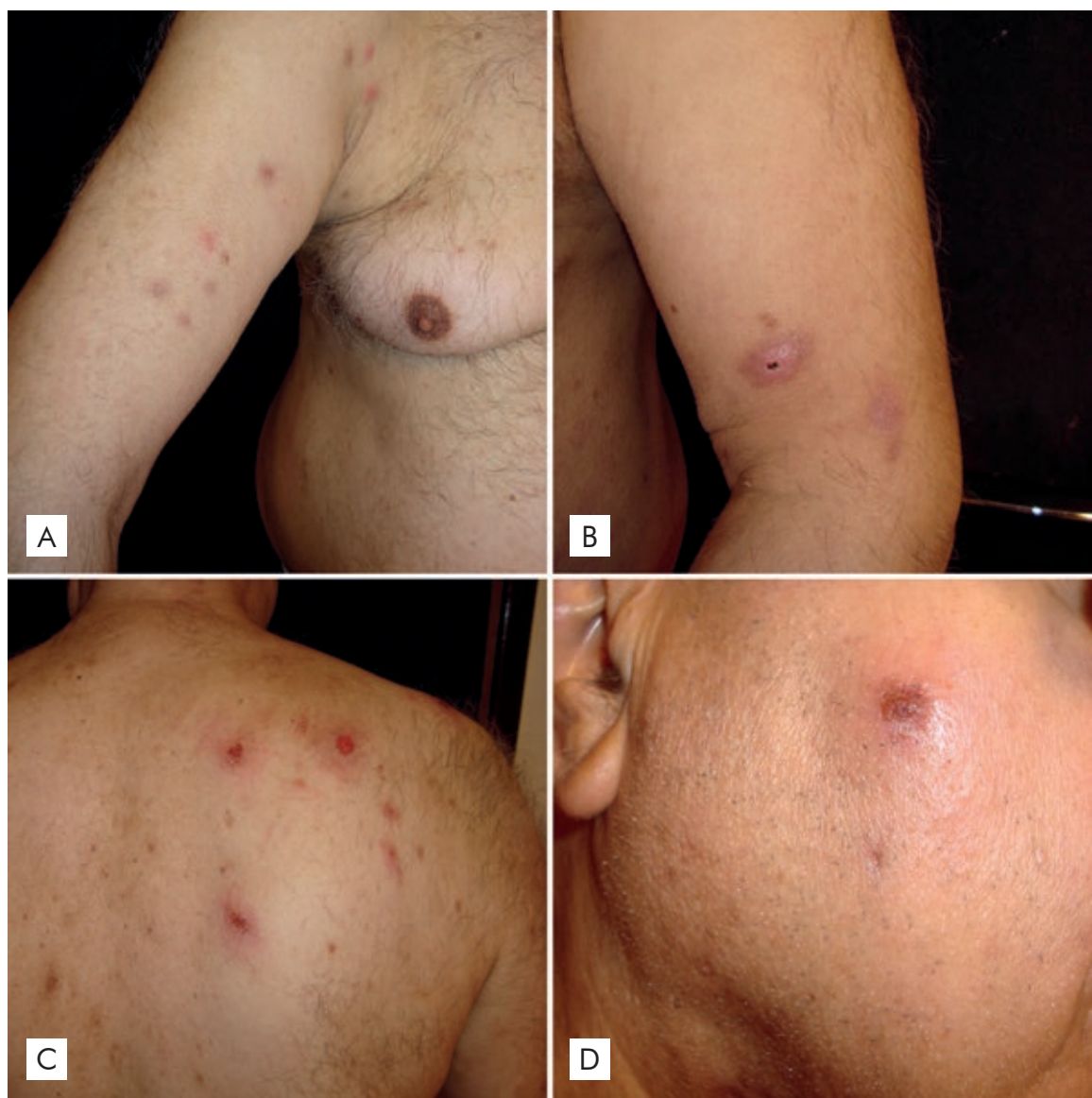

Fig 1 - A) Pápulas e pústulas centradas em folículos no braço direito; B) Nódulo eritematopurpúrico erosionado no braço esquerdo; C) Erosões centradas em folículos na região superior-direita do dorso; D) Nódulo eritematoso com crosta central na região geniana direita.

erosões centradas nos folículos (Fig. 1). A biopsia de uma das lesões mostrou um infiltrado linfocitário e esosinofílico a circundar e infiltrar os folículos pilosos, causando, focalmente, disrupção dos mesmos (Fig. 2). Com estes achados fez-se o diagnóstico de foliculite eosinofílica (FE).

Foram tentados diversos esquemas terapêuticos. A corticoterapia tópica isolada e em associação com minociclina $100 \mathrm{mg}$ qid foi ineficaz. Tentou-se posteriormente indometacina $75 \mathrm{mg}$ bid com sucesso parcial durante os primeiros 6 meses, ocorrendo posteriormente recrudescência das lesões.

Durante este período, o doente teve vários internamentos pelo agravamento das lesões cutâneas, e 2 episódios de sépsis, em que se suspeitou de um ponto de partida cutâneo.

Estes dados levaram a uma decisão conjunta com o Serviço de Hematologia, em que se decidiu instituir terapêutica mensal com imunoglobulina humana poliespecífica (IVlg). Assistiu-se a uma quase completa regressão das lesões cutâneas, a qual se mantém ao fim de 3 anos de seguimento.

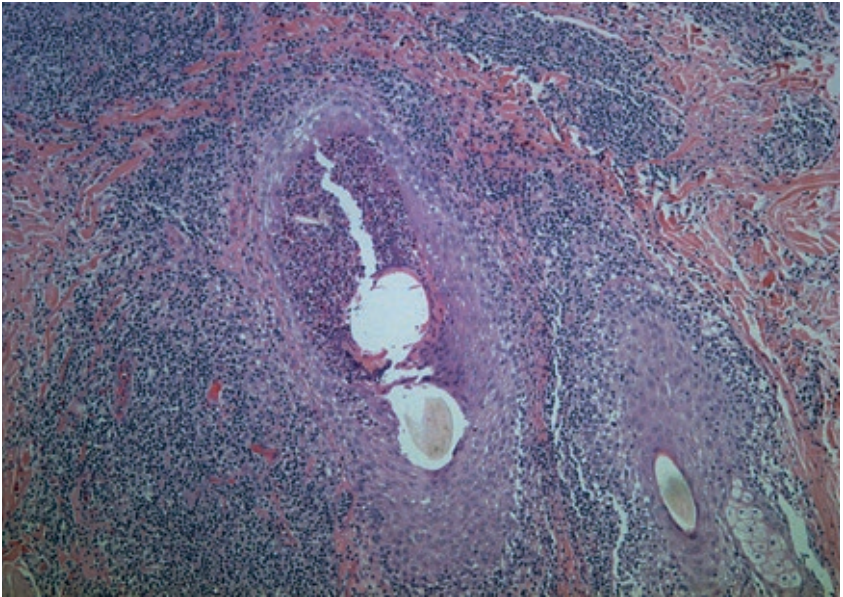

Fig 2 - Histopatologia de uma erosão. Infiltrado linfocítico e eosinofílico em torno de um folículo piloso parcialmente destruído (H\&E, x100). 


\section{Carta ao Editor}

\section{DISCUSSÃO}

A FE, cuja patogénese se mantém relativamente inexplicada, foi inicialmente descrita no Japão por Ofuji. Para além desta variante clássica, pouco frequente fora do japão, foram identificadas outras duas variantes, uma associada a imunodeficiência e uma variante infantil. Na variante associada a imunodeficiência, a infecção VlH é a causa mais frequente, secundada pelas neoplasias hematológicas. ${ }^{1,2}$

Neste contexto de imunossupressão, a FE representa um desafio terapêutico quando a reconstituição imunológica não é possível. A indometacina é a única terapêutica sistémica consensual, embora haja relatos de eficácia com outros fármacos, nomeadamente minociclina, ciclosporina, PUVA, dapsona, IFN-Y e tacrolimus tópico. ${ }^{3}$

Pode-se especular sobre uma acção directa da IVlg na FE dadas as suas propriedades imunomodeladoras. Contudo, o sucesso que se obteve com IVlg pode, com maior grau de certeza, ser atribuído à melhoria do estado imunológico do doente, o qual se encontrava comprometido pela LLC..$^{4,5}$

\section{REFERÊNCIAS}

1. Ofuji S, Ogino A, Horio T, Oseko T, Uehara M. Eosinophilic pustular folliculitis. Acta Derm Venereol. 1970; 50:195-203.

2. Katoh M, Nomura T, Miyachi Y, Kabashima K. Eosinophilic pustular folliculitis: a review of the Japanese published works. J Dermatol. 2013; 40:15-20.

3. Ono S, Yamamoto Y, Otsuka A, Kabashima K, Miyachi Y. Evaluation of the effectiveness of antibiotics against eosinophilic pustular folliculitis. Case Rep Dermatol. 2013; 5:144-7.

4. Anthony RM, Kobayashi T, Wermeling F, Ravetch JV. Intravenous gammaglobulin suppresses inflammation through a novel $\mathrm{T}(\mathrm{H}) 2$ pathway. Nature. 2011; 475:110-3.

5. Hagiwara A, Fujimura T, Furudate $S$, Kambayashi $Y$, Kagatani $S$, Aiba S. Induction of CD163+ M2 macrophages in the lesional skin of eosinophilic pustular folliculitis. Acta Derm Venereol. 2014; 94:104-6. 